\title{
Endoscopy can do more for Removal of Hypertension Intracerebral Hemorrhage
}

\author{
Maowu Fu, Jialiang Yang and Rucai Zhan* \\ The First Hospital Affiliated with Shandong First Medical University, Shandong First Medical University, China \\ *Corresponding author: Rucai Zhan, The First Hospital Affiliated with Shandong First Medical University, Shandong First \\ Medical University, China
}

\begin{tabular}{|c|c|}
\hline ARTICLE INFO & ABSTRACT \\
\hline Received: 慧 April 29, 2019 & alled a disease of "disability or death" due to \\
\hline Published: 慧 May 03, 2019 & high disability rate, high mortality rate, and also high economic burden for patient's family. \\
\hline $\begin{array}{l}\text { Citation: Maowu Fu, Jialiang Yang, Ru- } \\
\text { cai Zhan. Endoscopy can do more for } \\
\text { Removal of Hypertension Intracerebral } \\
\text { Hemorrhage. Biomed J Sci \& Tech Res } \\
\text { 17(4)-2019. BJSTR. MS.ID.003045. }\end{array}$ & $\begin{array}{l}\text { many advantages in evacuation of Supratentorial intracerebral hemorrhage includes basal } \\
\text { ganglia hemorrhage and intraventricular hemorrhage, as well for cerebellar hemorrhage, } \\
\text { such as minimally invasive, rapid, safe and effective. Combined with advanced location } \\
\text { technology, such as imaging navigation, merged reality, endoscopic surgery may provide } \\
\text { an effective, safe and rapid evacuation of brainstem hemorrhage with good outcomes. }\end{array}$ \\
\hline
\end{tabular}

\section{Opinion}

Being most severe morbidity of hypertension, Intracerebral Hemorrhage (HICH) was called a disease of "disability or death" due to high disability rate, high mortality rate, and also high economic burden for patient's family [1,2]. It is crucial that taking some effective methods to treat this disease, however, the surgical management for HICH remain controversial, because every surgical method has its own shortages, for example, craniotomy often results to large trauma for brain and bad prognosis, even death, craniopuncture may be associated with long time of drainage of hemorrhage, and infections, such as pneumonia, intracranial infection. In the recent two decades, as a new minimally invasive technique, endoscopy play an important role in removing HICH. Endoscopic evacuation for supratentorial intracerebral hemorrhage. Supratentorial intracerebral hemorrhage includes basal ganglia hemorrhage and intraventricular hemorrhage, which account for most of HICH. As the location of hemorrhage, the operating position is easy to set and endoscopy is convenient to be performed. Xin Z reported their case study [3], 100 patients were randomized into the endoscopic surgery group and the conservative treatment group, and found endoscopic group has better outcomes compared with the conservative group.

Endoscopic surgery presented many evident advantages in the removal of HICH [4], such as reducing manipulation of viable brain tissue, small incision and the delicate craniotomy, and better recovery. Endoscopic evacuation for cerebellar hemorrhage. Cerebellar hemorrhage is acute and life threatening due to mass effect causing compression of brain stem and fourth ventricle, so removing hemorrhage of the posterior fossa as early as possible is crucial to save patient's life. Craniectomy and craniopuncture are alternative for removal of a cerebellar hemorrhage. However, the most common complication is wound problem, such as bad healing, infections, and Cerebrospinal Fluid (CSF) leakage. So postoperative wound is hard to manage. Bad postoperative management may result in failure of the entire treatment. For endoscopic approach, we can make a paramedic incision and small bone window, which can decrease the rate of pressing the wound. Endoscopic surgery can provide a safe, rapid and effective removal of cerebellar hemorrhage, especially for patient whose brain stem being compressed by a mass effect [5]. Brainstem hemorrhage is a disease with a bad prognosis no matter surgical management or conventional treatment.

Being retraction of brain tissue during craniectomy surgery can injury brain which may result in death of patient. Craniopuncture for drainage of hemorrhage is a minimally invasive method, but blind puncture is still a problem and often take a long time for preformation, even using stereoscopic or imaging navigation. Endoscopic surgery has shown many of the advantages in removal of 
supratentorial and cerebellar hemorrhage. There is no previously report to document the endoscopic management for brainstem hemorrhage. And endoscopy can do more in removal of intracerebral hemorrhage, I believe, combined with advanced location technology, such as imaging navigation, merged reality, endoscopic surgery may provide an effective, safe and rapid evacuation of brainstem hemorrhage.

In conclusion, endoscopic surgery is a minimally invasive, safe and effective way for management of intracerebral hemorrhage, and endoscopy can do more and go far in the future.

\section{References}

1. Luengo Fernandez R, Gray AM, Rothwell PM (2009) Costs of stroke using patient-level data: A critical review of the literature. Stroke 40: e18-e23.

\section{ISSN: 2574-1241}

DOI: 10.26717/BJSTR.2019.17.003045

Rucai Zhan. Biomed J Sci \& Tech Res

(c) (P) This work is licensed under Creative

Submission Link: https://biomedres.us/submit-manuscript.php
2. Taylor TN, Davis PH, Torner JC, Holmes J, Meyer JW, et al. (1996) Lifetime cost of stroke in the United States. Stroke 27: 1459-1466.

3. Xin Zan, Hao Li, Wenke Liu, Yuan Fang, Junpeng Ma, et al. (2012) Endoscopic surgery versus conservative treatment for the moderatevolume hematoma in spontaneous basal ganglia hemorrhage (ECMOH): Study protocol for a randomized controlled trial. BMC Neurology 12: 34

4. Yad Ram Yadav, Gaurav Mukerji, Ravikiran Shenoy, Abhijeet Basoor, Gaurav Jain, et al. (2007) Endoscopic management of hypertensive intraventricular haemorrhage with obstructive hydrocephalus. BMC Neurology 7: 1 .

5. Lihong Li, Zhihong Li, Yuqian Li, Rujuan Su, Bao Wang, et al. (2018) Surgical evacuation of spontaneous cerebellar hemorrhage: comparison of safety and efficacy of suboccipital craniotomy, stereotactic aspiration, and thrombolysis and endoscopic surgery. World Neurosurg 117: e90-e98.

$\begin{array}{ll}\text { BIOMEDICAL } & \text { Assets of Publishing with us } \\ \text { RESEARCHES } & \text { - Global archiving of articles } \\ & \text { - Immediate, unrestricted online access } \\ & \text { - Rigorous Peer Review Process } \\ \end{array}$

